\title{
Dual muscle-liver transduction imposes immune tolerance for muscle transgene engraftment despite preexisting immunity
}

Laurent Bartolo,, Stéphanie Li Chung Tong, ${ }^{1}$ Pascal Chappert, ${ }^{1}$ Dominique Urbain, ${ }^{1}$ Fanny Collaud, ${ }^{2}$ Pasqualina Colella, ${ }^{2}$ Isabelle Richard, ${ }^{2}$ Giuseppe Ronzitti, ${ }^{2}$ Jocelyne Demengeot, ${ }^{3}$ David A. Gross, ${ }^{1}$ Federico Mingozzi, ${ }^{2}$ and Jean Davoust ${ }^{1}$

IInstitut Necker Enfants-Malades, Paris, France; Université Paris Descartes, Sorbonne Paris Cité, Faculté de Médecine, Paris, France; INSERM, U1151, Paris, France; CNRS UMR 8253, Paris, France. ²Itegrare Research Unit UMR S951, Genethon, INSERM, Université Evry, Université Paris Saclay, École Pratique des Hautes Études, Evry, France. ${ }^{3}$ Instituto Gulbenkian de Ciência, Oeiras, Portugal.

Immune responses to therapeutic transgenes are a potential hurdle to treat monogenic muscle disorders. These responses result from the neutralizing activity of transgene-specific B cells and cytotoxic T cells recruited upon gene transfer. We explored here how dual muscle-liver expression of a foreign transgene allows muscle transgene engraftment after adenoassociated viral vector delivery. We found in particular that induction of transgene-specific tolerance is imposed by concurrent muscle and liver targeting, resulting in the absence of $C D 8^{+} T$ cell responses to the transgene. This tolerance can be temporally decoupled, because transgene engraftment can be achieved in muscle weeks after liver transduction. Importantly, transgene-specific CD8 ${ }^{+} \mathbf{T}$ cell tolerance can be established despite preexisting immunity to the transgene. Whenever preexisting, transgene-specific $\mathrm{CD}^{+}$and $\mathrm{CD}^{+}$memory $\mathrm{T}$ cell responses are present, dual muscleliver transduction turns polyclonal, transgene-specific $\mathrm{CD8}^{+} \mathrm{T}$ cells into typically exhausted $\mathrm{T}$ cells with high programmed cell death 1 (PD-1) expression and lack of IFN- $\gamma$ production. Our results demonstrate that successful transduction of muscle tissue can be achieved through liver-mediated control of humoral and cytotoxic T cell responses, even in the presence of preexisting immunity to the muscle-associated transgene.

Conflict of interest: FM is an employee of Spark Therapeutics Inc.

Copyright: (c) 2019 American Society for Clinical Investigation

Submitted: December 21, 2018

Accepted: April 11, 2019

Published: May 16, 2019

Reference information: /CI Insight. 2019;4(10):e127008. https://doi. org/10.1172/jici.insight.127008

\section{Introduction}

Recombinant adenoassociated virus (rAAV) vectors are widely used for gene transfer applications in peripheral tissues and have been proved to safely deliver a variety of therapeutic transgenes to treat afflictions of monogenic origin, such as neuromuscular (1), ocular (2), neurodegenerative (3), and hemophilia (4) disorders. These gene-reparative medicine applications rely on successful engraftment of a defined transgene in the tissue of interest. Compared with classical tissue engraftment procedures involving the transfer of allogenic cells and MHC components, rAAV gene transfer raises specific concerns related to the immunogenicity of rAAV capsids and the processing and recognition of a newly expressed transgene by the host immune system. Preexisting anticapsid antibody responses observed for adenoassociated virus (AAV) serotypes, prevalent mostly in humans $(5,6)$, can impair treatment effectiveness (7), which advocates for the use of other rAAV serotypes, engineered capsids (8), and immunosuppression procedures (9). Of equal importance, cytotoxic T cell (CTL) responses to the capsid were encountered in human liver clinical trials (10), representing an important concern that is currently handled with transient immunosuppression regimens (11).

Parallel to anticapsid responses, immune responses to newly expressed transgenes depend on multiple factors intrinsic to the recipient, such as the mutational genotype of the host, the route of injection, the promotor being used, the rAAV dose, and the initial inflammatory and metabolic disorder status present in the tissue to be injected (12). The occurrence of preexisting immune responses to the transgene represents another challenging issue. In the case of patients with hemophilia B, preexisting humoral responses against coagulation factor IX (FIX) have been observed in humans in relation with protein replacement therapies $(13,14)$. Animal studies have also evidenced immune responses to FIX gene transfer, especially in FIX-KO animals, 
A

rAAV1/mOVA i.m.

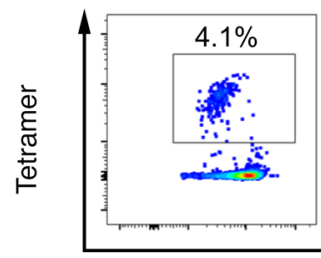

C rAAV1/mOVA i.m.

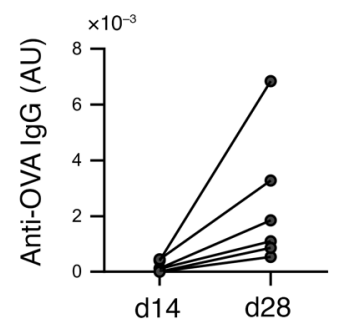

rAAV1/mOVA i.m. rAAV8/mOVA i.v.

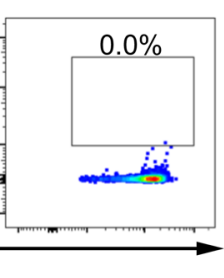

CD8

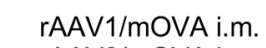
rAAV8/mOVA i.v.

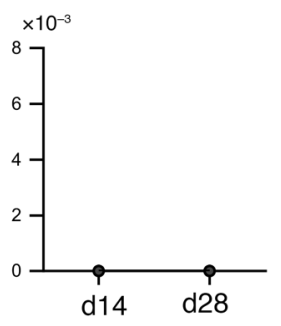

B

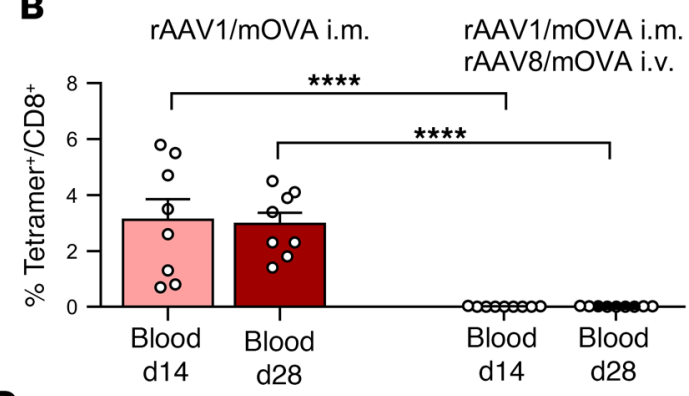

D

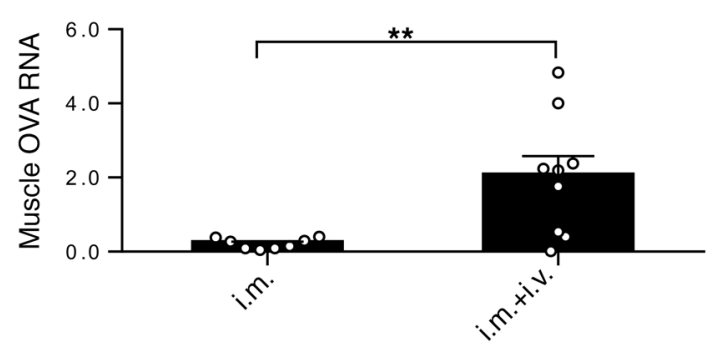

Figure 1. Transgene-specific immune tolerance in muscle is imposed by concurrent liver targeting. Male C57BL/6 mice were injected in the left tibialis anterior muscle with $10^{9}$ viral genomes $(\mathrm{vg})$ of rAAV1 encoding mOVA under the muscle-specific SPc5-12 promotor and injected i.v. with $1 \times 10^{10} \mathrm{vg}$ rAAV8 encoding mOVA under the liver-specific promotor hAAT. Experimental conditions listed correspond to rAAV1/mOVA i.m. injection and to simultaneous injections of rAAV1/mOVA i.m. and rAAV8/mOVA i.v. Lymphocytes were extracted from blood at day 14 and day 28 to analyze OVA-specific CD8 ${ }^{+} \mathrm{T}_{\text {cells }}$ by $\mathrm{Kb} / \mathrm{OVA}_{257}$ tetramer staining and cytometry. (A) Representative dot plots at day 28 and (B) frequencies of $\mathrm{CD}^{+} \mathrm{Kb}^{\mathrm{OVVA}}{ }_{257}$ tetramer (tetramer $^{+}$) in blood gated on CD8 ${ }^{+} \mathrm{T}$ cells. (C) Concentration of anti-OVA IgG relative to a control serum in AU. (D) Reverse transcription quantitative PCR (RT-qPCR) performed in muscle at day 29 in the experimental conditions listed. RT-qPCR results are expressed relative to OVA RNA expression in the "i.m. + i.v." group (see Methods). Each dot represents an individual animal, mean $\pm \operatorname{SEM}\left(n=9\right.$ mice per group, pooled from 3 independent experiments). ${ }^{* *} P<0.01,{ }^{* * *} P<0.0001$ (Mann-Whitney test).

in which the FIX transgene is considered a foreign antigen by the immune system (15-17). This points out the important role of the genetic background of the host in the generation of transgene-specific $\mathrm{T}$ cells, and multiple genetic components concur in defining the immune response to a given transgene. As an example, cytotoxic $\mathrm{CD}^{+} \mathrm{T}$ cell responses were observed after human FIX gene transfer in C57BL/6 mice but were absent in other mouse strains (18). The target tissue itself is also an important factor influencing the outcome of immune responses after gene transfer (11) and rAAV muscle targeting is known to be highly immunogenic using model transgenes (19) but also with cell-associated transgene delivery to treat monogenic muscle disorders (20-23). Of note, the presence of preexisting circulating $\mathrm{T}$ cell immunity to dystrophin was observed in a sizable proportion of patients with Duchenne muscular dystrophy (DMD) $(24,25)$, possibly driving the immune-mediated rejection of the microdystrophin transgene delivered intramuscularly with AAV vectors $(20,22,25)$, which advocates for transgene-specific immunomodulation.

As for harnessing the tolerogenic properties of the liver, reports showed that expression of an allogenic MHC component in the liver allowed successful engraftment of a transgenic skin graft bearing the same allogenic MHC antigen $(26,27)$. Likewise, rAAV-mediated liver targeting proved safe and efficient in hemophilia mouse models with a human FIX transgene or using a variety of transgenes and rAAV serotypes (28-30). rAAV FIX gene transfer in the liver induced no noticeable humoral or cellular responses against the transgene, and this tolerance state was conserved after secondary FIX immunization in rodents (31). Moreover, recent mouse studies showed that rAAV FIX liver targeting can override preexisting antitransgene humoral immunity (14). Regarding CTL responses to the transgene, the capacity of liver transduction to control the fate of transgene-specific TCR-transgenic $\mathrm{CD} 8^{+} \mathrm{T}$ cells was initially unraveled by Bertolino and colleagues, who showed that the site of primary $\mathrm{T}$ cell activation dictates the balance between intrahepatic tolerance and immunity (32), a result confirmed with other models (33). The fraction of transduced hepatocytes was critical to induce immune tolerance after hepatic gene transfer, leading to the acquisition of an exhausted phenotype for TCR-transgenic $\mathrm{CD} 8^{+} \mathrm{T}$ cells $(34,35)$. Considering the fact that muscle transduction leads to the generation of prominent humoral and cellular immune responses to the transgene (19), we studied here how dual muscle-liver transduction could control these polyclonal 
A

AAV8/mOVA i.v. $\quad$ AAV1/mOVA i.m.

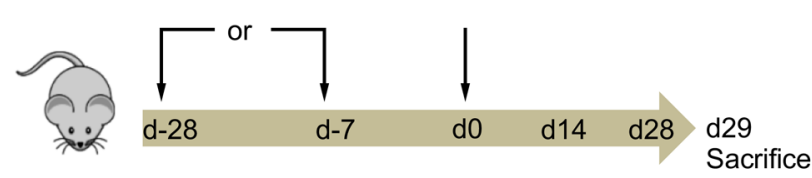

B

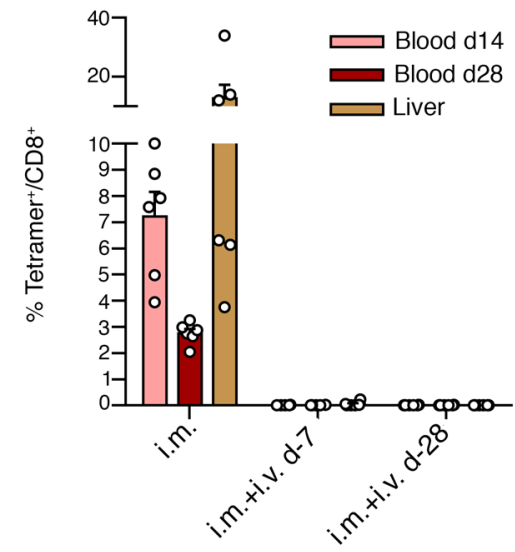

C

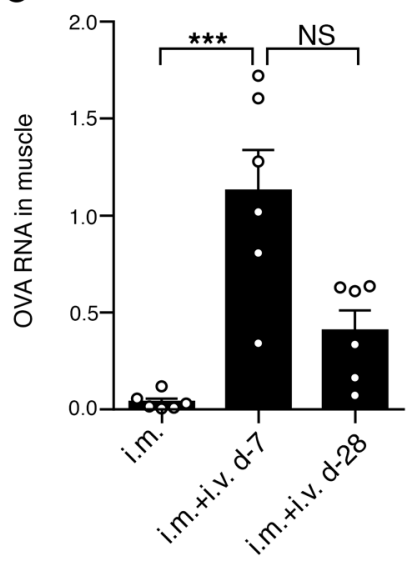

Figure 2. Transgene-specific CD8+ $\mathbf{T}$ cell tolerance is established in muscle, long after liver transduction. Male C57BL/6 mice were injected i.v. with $1 \times 10^{10} \mathrm{vg}$ of rAAV8/mOVA at day -28 or -7 or not (control group). At day 0 , mice were injected in the left tibialis anterior muscle with $1 \times 10^{10} \mathrm{vg}$ of rAAV1/mOVA i.m. Blood was collected at day 14 and day 28 , and mice were euthanized at day 29 to collect injected muscle and liver. (A) Time line of the experiment. (B) Frequency of tetramer ${ }^{+}$ gated on $\mathrm{CD}^{+} \mathrm{T}$ cells assessed at day 28 in the 3 experimental conditions listed. (C) RT-qPCR performed in muscle at day 29 in the 3 experimental conditions listed. RT-qPCR results are expressed relative to OVA RNA expression in the "i.m. + i.v. d-7" group. Each dot represents an individual animal, mean \pm SEM ( $n=6$ mice per group, pooled from 2 independent experiments). ns $P>0.05,{ }^{* * *} P<0.001$ (Kruskal-Wallis test followed by Dunn's multiple-comparisons test).

responses typically initiated in muscle-draining lymph nodes. Moreover, little is known about the influence of preexisting immunity to muscle-associated transgenes $(24,25)$, and we wished to delineate the role of preexisting $\mathrm{CD}^{+}$and $\mathrm{CD} 4^{+} \mathrm{T}$ cell immunity on the reactivation of $\mathrm{CD} 8^{+} \mathrm{T}$ cells in the presence of dual muscle-liver transduction.

Using a highly immunogenic OVA transgene well adapted to decipher specific $\mathrm{T}$ cell responses, we found here that dual muscle-liver rAAV transduction imposes sustained tolerance to both anti-transgene $\mathrm{CD}^{+} \mathrm{T}$ cell and humoral responses generated by rAAV muscle transduction. Importantly, in the presence of preimmune material comprising $\mathrm{CD}^{+}$and $\mathrm{CD}^{+} \mathrm{T}$ cells, this tolerance induction is shown to operate through partial deletion of - and induction of exhaustion in - transgene-specific $\mathrm{CD}^{+} \mathrm{T}$ cells. Our results demonstrate that liver rAAV transduction imposes immune tolerance to an entire transgene-specific $\mathrm{T}$ cell repertoire elicited after muscle transduction, regardless of preexisting immune responses to the transgene.

\section{Results}

Transgene-specific immune tolerance is established by dual muscle-liver transduction. To establish that rAAV liver transduction promotes immune tolerance toward muscle transgene engraftment, we choose a model transgene encoding for a membrane form of OVA (mOVA), which was reported to be highly immunogenic after rAAV gene transfer in muscle (19). For the transfer, 2 vectors were designed: a muscle-tropic rAAV1 vector encoding mOVA under the muscle-specific promotor SPc5-12 and a liver-tropic rAAV8 vector encoding for the same mOVA transgene under the liver-specific promoter hAAT (Supplemental Figure 1; supplemental material available online with this article; https://doi.org/10.1172/jci.insight.127008DS1). As expected, $\mathrm{rAAV} 1 / \mathrm{mOVA}$ vector intramuscular (i.m.) injection induced a strong anti-OVA CD8 ${ }^{+} \mathrm{Kb} / \mathrm{OVA}_{257}$ tetramer $^{+}$ (tetramer ${ }^{+}$) T cell response in blood at day 14 and day 28 after injection (Figure 1, A and B), resulting in a significant decrease in OVA expression in muscle by day 29 (Figure 1D), indicative of immune-related transgene rejection. Of note, analysis of liver lymphocyte populations evidenced an enriched proportion of 
A

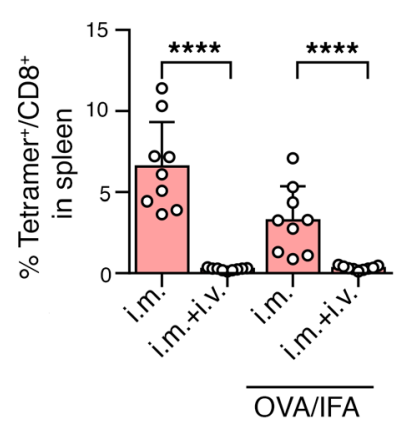

B

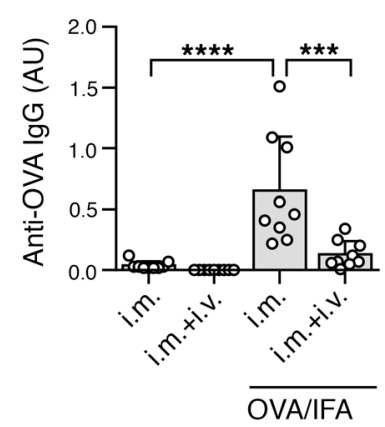

C

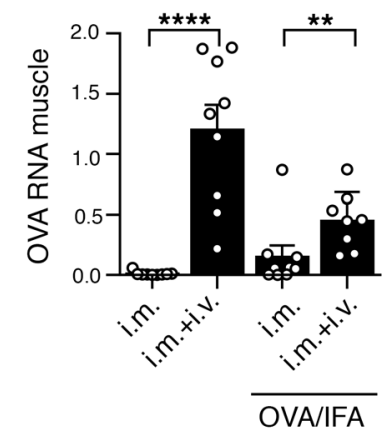

Figure 3. Transgene-specific CD8+ $\mathrm{T}$ cell tolerance occurs in muscle despite prior immunization. Male C57BL/6 mice were immunized or not with OVA emulsified in incomplete Freund's adjuvant (IFA) by tail base injection at day 0 , then injected with rAAV vectors at day 14 . Blood was collected at day 28, and mice were euthanized at day 29 to collect spleen and injected muscle. The rAAV1/mOVA i.m. and the rAAV8/mOVA i.v. injections were performed as described in Figure 1. The rAAV1/mOVA i.m. injection was performed with $1 \times 10^{10} \mathrm{vg}$ to refine our analysis of $\mathrm{T}$ cell populations. Lymphocytes were extracted from spleens to perform $\mathrm{Kb} / \mathrm{OVA}_{257}$ tetramer staining. (A) Frequencies of tetramer ${ }^{+}$gated on $\mathrm{CD}^{+} \mathrm{T}^{+}$cells in spleens. (B) Quantities of anti-OVA IgG relative to a control serum in AU. (C) RT-qPCR performed in muscle at day 29 in the 4 experimental conditions listed. RT-qPCR results are expressed relative to OVA RNA expression in the "i.m. + i.v." nonimmunized group. Each dot represents an individual animal, mean \pm SEM $(n=9$ mice per group, pooled from 3 independent experiments). ${ }^{* *} P<0.01,{ }^{* *} P<0.001,{ }^{* * *} P<0.0001$ (Mann-Whitney test).

anti-OVA CD8 ${ }^{+} \mathrm{T}$ cells compared with blood (Supplemental Figure 2), a result consistent with a previous report showing that activated $\mathrm{CD} 8^{+} \mathrm{T}$ cells can accumulate in the liver independently of antigen recognition (36). These transgene-specific $\mathrm{CD}^{+} \mathrm{T}$ cell responses are associated with humoral responses to OVA (Figure 1C). Taken together, these results show that $\mathrm{rAAV} 1 / \mathrm{mOVA}$ muscle targeting induced cellular and humoral responses associated with transgene rejection.

In parallel, we assessed the capacity of the liver-tropic rAAV8/mOVA vector to alleviate transgene immune responses and rejection. $\mathrm{rAAV} 8 / \mathrm{mOVA}$ caudal vein i.v. injection of $1 \times 10^{10}$ viral genomes $(\mathrm{vg})$ induced neither anti-OVA tetramer ${ }^{+} \mathrm{CD}^{+} \mathrm{T}$ cell response in blood at day 14 and day 28 nor anti-OVA antibody responses (data not shown). Liver mOVA expression was confirmed by RT-qPCR under these conditions (data not shown), attesting to long-term acceptance of the transgene product in accordance with the lack of cellular and humoral responses to the transgene. Next, using concurrent i.m. and i.v. injections of the muscle-tropic rAAV1 and liver-tropic rAAV8 vectors, respectively, we found no anti-OVA $\mathrm{CD}^{+} \mathrm{T}$ cell response in blood at day 14 and day 28 (Figure 1, A and B) and in liver lymphocyte populations at day 29 (Supplemental Figure 2), as well as no OVA antibody responses (Figure 1C). Maintenance of transgene expression was effective in both muscle (Figure 1D) and liver (data not shown), attesting to lack of immune rejection. Next, we evaluated the specificity of this suppression and injected rAAV1/ mOVA to target the muscle concurrently with an irrelevant rAAV8/hAAT-hepatic FIX (hFIX) to target the liver and evidenced cellular and humoral responses against OVA similar to the i.m.-only rAAV1/ mOVA injection condition (Supplemental Figure 3, A-C). Here, the presence of dissimilar transgenes in muscle and liver led to complete rejection of the mOVA transgene in muscle (Supplemental Figure 3D) with full acceptance of the hFIX transgene in the liver (data not shown). This result indicates that the tolerance induction process requires dual expression of the same transgene in muscle and liver. Of note, we observed no reduction in the humoral responses to the rAAV1 and rAAV8 capsids with the dual muscle-liver transduction protocol (data not shown). We also assessed the eventual tolerizing effect of $\mathrm{rAAV} 1 / \mathrm{mOVA}$ leakage from the blood circulation to the liver and found that $\mathrm{rAAV} 1 / \mathrm{mOVA}$ injection performed using the i.v. route was unable to confer immune protection for muscle transduction (data not shown), indicating that actual rAAV8/hAAT-mOVA liver targeting is mandatory to promote transgene-specific tolerance. To complement these results, we engineered a second set of rAAV vectors encoding for a mOVA-GFP construct, where the full-length EGFP is fused after the transmembrane part of mOVA (Supplemental Figure 1), and found similar requirements for dual muscle-liver expression of the same transgene to achieve muscle transgene engraftment (Supplemental Figure 4). Of note, the mOVAGFP construct harbors a MHC class II (MHCII) epitope, which leads to the induction of detectable 
A

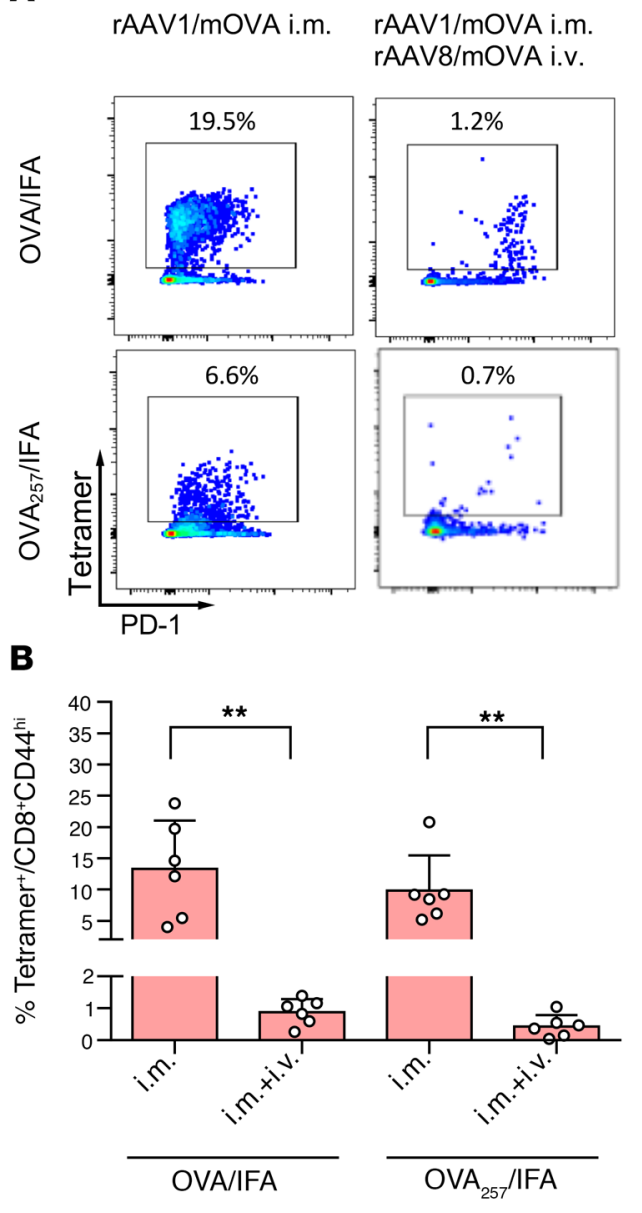

C
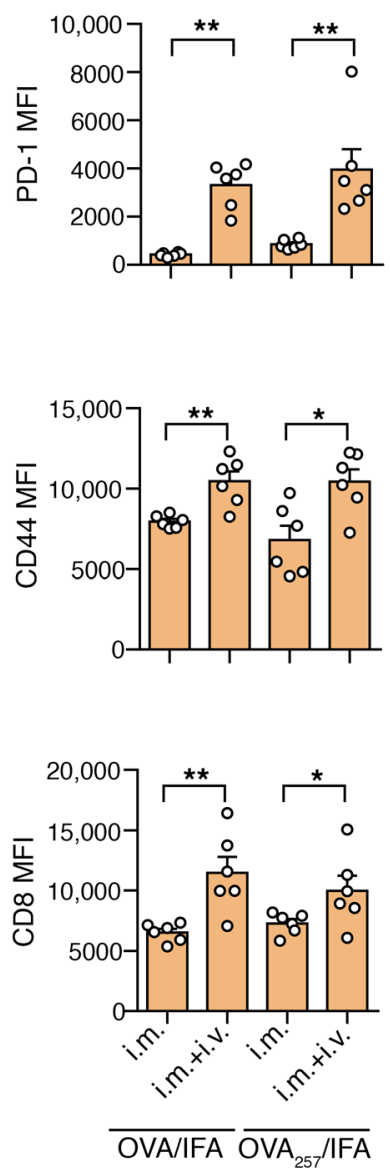

Figure 4. Residual OVA-specific $\mathrm{CDB}^{+} \mathrm{T}$ cells harbor a high-programmed cell death 1 phenotype after prior immunization and tolerance induction. Male C57BL/6 mice were immunized or not with OVA or OVA ${ }_{257}$ emulsified in IFA (OVA) IFA or $\left.\mathrm{OVA}_{257} / \mathrm{IFA}\right)$ and injected as described in Figure $3\left(1 \times 10^{10} \mathrm{vg}\right.$ of rAAV1-mOVA i.m. and rAAV8-mOVA i.v.). (A) Representative dot plots of tetramer and programmed cell death 1-positive (PD-1+) T cells gated on CD8 ${ }^{+} \mathrm{CD} 44^{\text {hi }}$ T cells in spleens assessed at day 28 in the 4 experimental conditions listed. (B) Frequency of tetramer ${ }^{+} \mathrm{T}$ cells gated on CD8 ${ }^{+}$CD44 ${ }^{\text {hi }} T$ cells in spleens assessed at day 28 in the 6 experimental conditions listed. (C) MFI of expression levels of PD-1 (upper), CD44 (middle) and CD8 (lower) gated on CD8 ${ }^{+} C D 44^{+}$tetramer ${ }^{+}$T cells after OVA/IFA or OVA ${ }_{257} /$ IFA immunization. Each dot represents an individual animal, mean \pm SEM ( $n=6$ mice per group, pooled from 2 independent experiments). ${ }^{*} P<0.05,{ }^{* *} P<0.01$ (Mann-Whitney test).

IFN- $\gamma$-producing $\mathrm{CD} 4^{+} \mathrm{T}$ cells and enhances OVA-specific antibody responses in mice initially primed with the corresponding GFP peptide (Supplemental Figure 4C). In conclusion, dual muscle and liver targeting with rAAV vectors is instrumental in eliminating the occurrence of cellular and humoral immune responses to the transgene and in allowing transgene expression in muscle.

We then explored the sustainability and robustness of this transgene-specific tolerance and injected the rAAV8/mOVA vector via the i.v. liver route before challenging the mice i.m. at day 7 or day 28 with rAAV1/ mOVA (Figure 2A). In both cases, we detected no humoral (data not shown) and limited cellular responses (Figure 2B), and OVA expression was significantly maintained in muscle compared with the control with rAAV1/mOVA i.m. injection alone (Figure 2C). To assess the robustness of this peripheral tolerance to mOVA, we challenged a second set of mice at day 7 or day 28 with rAAV1/mOVA-GFP i.m. injections (Supplemental Figure 5A), which harbored an immunoreactive MHCII epitope within the GFP sequence able to prime a $\mathrm{CD} 4^{+} \mathrm{T}$ cell response (Supplemental Figure $4 \mathrm{C}$ ). As before, we detected no humoral (data not shown) and limited cellular responses (Supplemental Figure 5B) and detected sustained OVA-GFP expression in muscle (Supplemental Figure 5C). Thus, this immune tolerance associated with liver transgene expression appears robust and long-lived even when using a muscle transgene harboring an additional MHCII epitope. 
A

rAAV1/mOVA i.m.
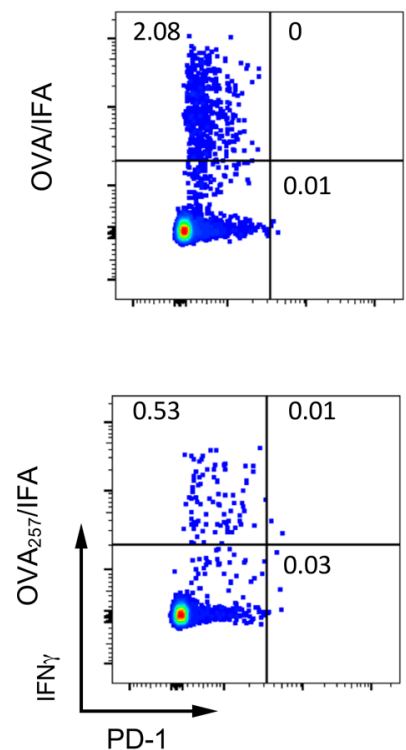

rAAV1/mOVA i.m rAAV8/mOVA i.v.
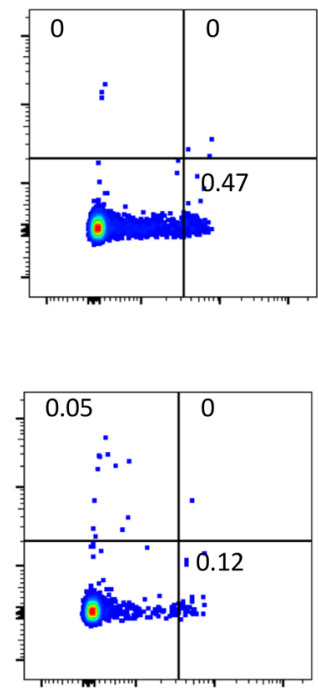

B

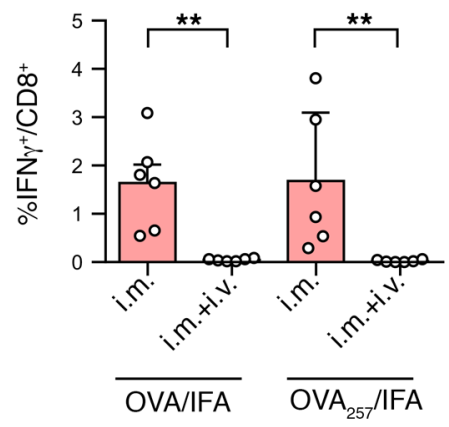

C

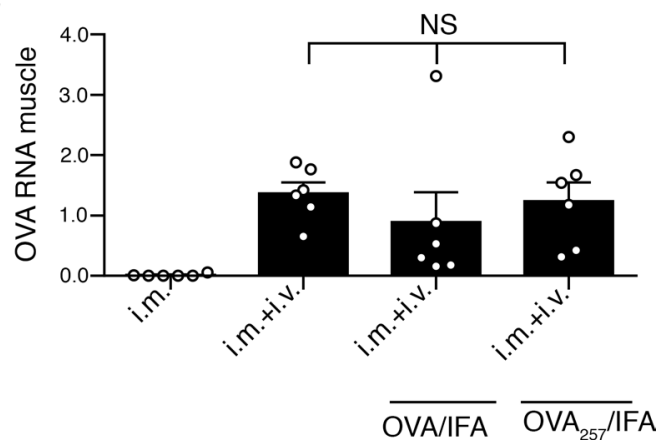

Figure 5. Lack of IFN- $\gamma$ production in residual OVA-specific PD- $\mathbf{1}^{\text {hi }} \mathbf{C D 8} 8^{+} \mathbf{T}$ cells. Splenocytes from male $\mathrm{C} 57 \mathrm{BL} / 6$ mice immunized or not with $\mathrm{OVA}$ or $\mathrm{OVA}_{257}$ emulsified in IFA (OVA/IFA or OVA 257 IFA) from the experiment presented in Figure 4 were stimulated 4 hours in vitro with OVA ${ }_{257}$ peptide and processed for intracellular staining. (A) Representative dot plots of $\mathrm{PD}-1^{+}$and IFN- $\gamma^{+}$splenocytes gated on CD8 $8^{+} \mathrm{T}$ cell populations after in vitro stimulation with $\mathrm{OVA}_{257}$ peptide. (B) Frequency of IFN- $\gamma^{+}$-producing cells gated on $\mathrm{CD}^{+} \mathrm{T}$ cells in spleens after in vitro stimulation with $\mathrm{OVA}{ }_{257}$ peptide. (C) RT-qPCR performed in muscle at day 29 in the 4 experimental conditions listed. RT-qPCR results are expressed relative to OVA RNA expression in the "i.m. + i.v." nonimmunized group. Each dot represents an individual animal, mean \pm SEM ( $n=6$ mice per group, pooled from 2 independent experiments). ns $P>0.05$, ${ }^{* *} P<0.01$ (Mann-Whitney test for $\mathbf{B}$ and Kruskal-Wallis test followed by Dunn's multiple comparisons for $\mathbf{C}$ ).

Induction of immune tolerance and of exhausted OVA-specific CD $8^{+} T$ cells in the presence of preexisting immunity. Having established that dual muscle-liver transduction allows muscle transgene engraftment, we assessed whether a preexisting immune response against the transgene product impairs the induction of transgene-specific tolerance. For that, mice were preimmunized or not with OVA protein emulsified in incomplete Freund's adjuvant (IFA) at day 0 and injected at day 14 with either single i.m. rAAV1/mOVA or dual i.m. rAAV1/mOVA and i.v. rAAV8/mOVA injections. As expected, OVA/IFA immunization was particularly effective to prime a humoral anti-OVA response monitored after i.m. rAAV1/mOVA injection (Figure 3B). Importantly, we found that dual i.m. rAAV1/mOVA and i.v. rAAV8/mOVA injections reduced OVA-specific $\mathrm{CD} 8^{+} \mathrm{T}$ cells responses and humoral responses to very low levels (Figure 3, A and B) and ensured long-term OVA expression in muscle (Figure 3C), despite preexisting immunity. Thus, the transgene-specific tolerance imposed by dual muscle-liver transduction overrides both emerging and memory $\mathrm{CD}^{+} \mathrm{T}$ cell as well as preexisting antibody responses to the transgene product.

As shown above, dual muscle-liver transduction is able to prevent adverse responses associated with preexisting transgene-specific immunity present in the host. Under these conditions, we noticed the presence of a residual fraction of transgene-specific $\mathrm{CD}^{+} \mathrm{T}$ cells in the spleens of mice initially primed with OVA/IFA and receiving i.v. rAAV8/mOVA injections (data not shown). Because OVA/IFA preimmunization did not compromise transgene muscle expression under these conditions (Figure 3C), we analyzed the phenotype of residual OVA-specific CD8 ${ }^{+} \mathrm{T}$ cells present after OVA/IFA or $\mathrm{OVA}_{257}$ peptide/IFA immunization followed by dual muscle-liver transduction (Figure 4). The $\mathrm{OVA}_{257}$ peptide/IFA injection condition was used to visualize the fate of transgene-specific $\mathrm{CD}^{+} \mathrm{T}$ cells independent of $\mathrm{CD}^{+} \mathrm{T}$ cell and $\mathrm{B}$ cell priming. In these latter 2 preimmunization conditions, dual muscle-liver transduction significantly reduced the quantity of OVA-specific $\mathrm{CD} 8^{+} \mathrm{T}$ cells compared with a single muscle rAAV transduction, with a residual fraction of OVA-specific CD $8^{+} \mathrm{T}$ cells present in both cases (Figure 4, A and B). Of great interest, we found that these residual OVA-specific CD8 ${ }^{+} \mathrm{T}$ cells expressed higher levels of programmed cell death 1 (PD-1) (Figure 4, A-C) and slightly higher levels of 
A

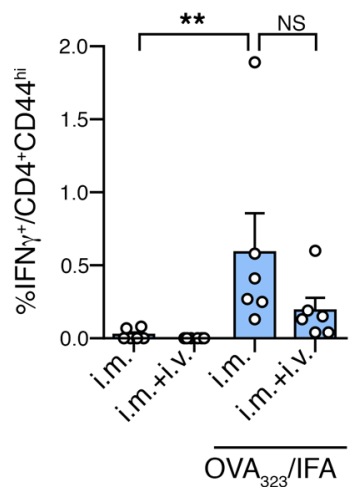

B

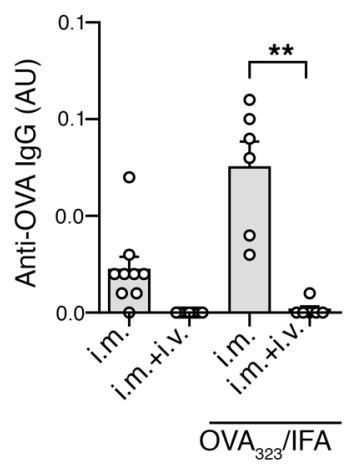

C

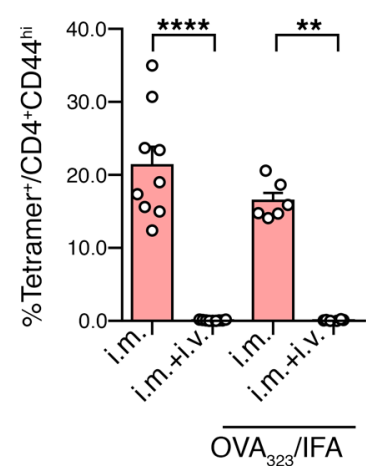

D

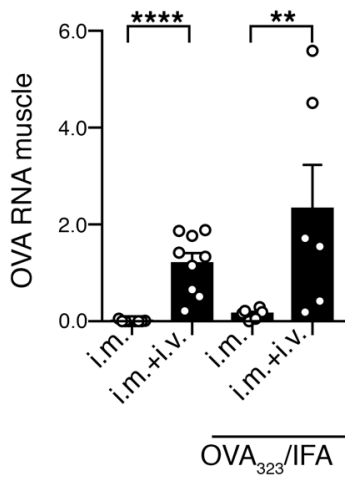

Figure 6. Transgene-specific $\mathbf{C D 8}{ }^{+} \mathbf{T}$ cell tolerance is established despite $\mathbf{C D 4}{ }^{+} \mathbf{T}$ cell immunization. Male $\mathrm{C57BL} / 6$ mice were immunized or not with the $\mathrm{OVA}_{323}$ peptide (MHCIl epitope) emulsified in IFA (OVA $\left.A_{323} / \mathrm{IFA}\right)$ and injected as described in Figure $3\left(1 \times 10^{10} \mathrm{vg}\right.$ of rAAV1-mOVA i.m. and rAAV8-mOVA i.v.). Lymphocytes were extracted from spleens to perform tetramer+ and intracellular IFN- $\gamma$ staining. (A) Frequency of IFN- $\gamma^{+}$gated on CD4+CD44 ${ }^{\text {hi }}$ T cells in spleens. (B) Quantities of anti-OVA IgG relative to a control serum in AU. (C) Frequency of tetramer gated on CD8 ${ }^{+}$CD44 hi $T$ cells in spleens. (D) RT- $q P C R$ performed in muscle at day 29 in the 4 experimental conditions listed. RT-qPCR results are expressed relative to OVA RNA expression in the "i.m. + i.v." nonimmunized group. Each dot represents an individual animal, mean \pm SEM ( $n=6-9$ mice per group, pooled from 2- 3 independent experiments). ns $P>0.05,{ }^{* *} P<0.01,{ }^{* * * *} P<0.0001$ (Mann-Whitney test).

CD44 and CD8 in comparison with those generated after muscle transduction alone (Figure 4C), raising the possibility of a conversion of OVA-specific $\mathrm{CD}^{+}$effector $\mathrm{T}$ cells into exhausted $\mathrm{CD} 8^{+} \mathrm{T}$ cells.

To qualify the functional ability of these residual OVA-specific CD $8^{+} \mathrm{T}$ cells, we assayed their ability to produce IFN- $\gamma$ in response to $\mathrm{MHCI}$-restricted $\mathrm{OVA}_{257}$ peptide stimulation in conjunction with $\mathrm{PD}-1$ surface expression (Figure 5). As evidenced by intracellular staining, muscle-only transduction with i.m. rAAV1/mOVA generated mostly OVA-specific $\mathrm{CD}^{+} \mathrm{T}$ cells with high IFN- $\gamma$ production and lower PD-1 surface expression, whereas dual muscle-liver transduction with i.m. rAAV1/mOVA and i.v. rAAV8/mOVA injections generated mostly residual OVA-specific CD8 ${ }^{+} \mathrm{T}$ cells with no IFN- $\gamma$ production capability (Figure 5A). Upon quantification, no IFN- $\gamma$ production was observed after simultaneous i.m. rAAV1/mOVA and i.v. rAAV8/mOVA injection in both OVA/IFA and $\mathrm{OVA}_{257} / \mathrm{IFA}$ preimmunization conditions (Figure 5B). Consequently, the residual OVA-specific CD8 ${ }^{+} \mathrm{T}$ cells expressing a high level of PD-1 observed after dual muscle-liver transduction (Figure 4) lacked IFN- $\gamma$ production capacity and corresponded to typically exhausted $\mathrm{CD} 8^{+} \mathrm{T}$ cells. Moreover, OVA muscle transgene engraftment was effective after dual i.m. rAAV1/mOVA and i.v. rAAV8/mOVA injections, independent of preimmunization (Figure $5 \mathrm{C}$ ). These results demonstrate that dual muscle-liver transduction is sufficient to protect muscle OVA expression even in presence of a preexisting $\mathrm{CD}^{+} \mathrm{T}$ cell immunity induced by OVA/IFA and $\mathrm{OVA}_{257}$ peptide/IFA, through a mechanism implying in part the generation of $\mathrm{CD} 8^{+} \mathrm{T}$ cells exhibiting a typically exhausted phenotype.

Transgene-specific $C D 8^{+} T$ cell tolerance is established despite preexisting $C D 4^{+} T$ cell responses. Last, because preexisting $\mathrm{CD}^{+} \mathrm{T}$ cell responses to dystrophin have been observed in DMD patients $(24,25)$, we wondered whether a preexisting OVA-specific $\mathrm{CD} 4^{+} \mathrm{T}$ cell response could influence the level of transgene-specific tolerance achieved after dual muscle-liver targeting. For that, mice were first immunized with the MHCII-restricted $\mathrm{OVA}_{323}$ epitope before being injected with either rAAV1/mOVA i.m. or dual rAAV1/ mOVA i.m. and rAAV8/mOVA i.v. As expected, we found that $\mathrm{OVA}_{323}$ immunization significantly primed IFN- $\gamma$ production in activated $\mathrm{CD} 4{ }^{+} \mathrm{CD} 44^{\mathrm{hi}} \mathrm{T}$ cells generated after single i.m. $\mathrm{rAAV} 1 / \mathrm{mOVA}$ injection (Figure 6A) and anti-OVA humoral response (Figure 6B). In mice injected with dual i.m. rAAV1/mOVA and i.v. rAAV8/mOVA, IFN- $\gamma$ production was equally detected in activated CD $4{ }^{+} \mathrm{CD} 44^{\text {hi }} \mathrm{T}$ cells (Figure 6A) without compromising muscle OVA expression (Figure 6D), in accordance with the lack of tetramer ${ }^{+}$ $\mathrm{CD}^{+} \mathrm{T}$ cell and humoral responses observed under these conditions (Figure 6, B and C). Altogether, although OVA $_{323}$ immunization was effective to boost antibody production (Figure 6B) after i.m. injection only, dual i.m. and i.v. injections were operant in controlling humoral and cellular $\mathrm{CD}^{+} \mathrm{T}$ cell, but not $\mathrm{CD}^{+} \mathrm{T}$ cell, responses to the transgene, and this controlling was sufficient to protect muscle OVA expression. Our results demonstrate that transgene-specific $\mathrm{CD}^{+} \mathrm{T}$ cell tolerance is established despite preexisting $\mathrm{CD}^{+} \mathrm{T}$ cell responses, which persisted after dual muscle-liver transduction. 


\section{Discussion}

Overcoming adaptive immune response to transgene products is of crucial importance for successful gene therapy of muscle monogenic disorders (37). Indeed, in a recent $\mathrm{rAAV} /$ microdystrophin clinical trial performed in patients with DMD (25), preexisting dystrophin-specific T cells were observed against epitopes present in the transgene product as well as in short dystrophin forms expressed in revertant fibers. Taking into account prior knowledge from coagulation hFIX studies evidencing the immunological benefits of liver transduction for hFIX tolerance induction $(31,38)$, we devised a dual muscle-liver transduction protocol able to impose transgene-specific immunological unresponsiveness for muscle transgene. Using a highly immunogenic membrane form of a model OVA transgene, we demonstrate that concurrent muscle-specific and liver-specific rAAV transduction neutralized adverse cytolytic and humoral immune responses and enabled long-term transgene expression in muscle despite the presence of preexisting immunity to the transgene.

Harnessing the properties of the liver as a tolerogenic organ (39-41), several reports have demonstrated that liver expression of systemic factors, such as coagulation FIX, can promote a state of transgene-specific tolerance $(28,29,31)$. Studies using adoptive transfer of transgene-specific TCR-transgenic $\mathrm{CD}^{+} \mathrm{T}$ cells showed that tolerance induction after liver transduction depends on several factors, including the site of primary naive $\mathrm{CD}^{+} \mathrm{T}$ cell activation, in essence in the liver or in draining lymph nodes (32), and the proportion of transgene-expressing cells in the liver $(34,35)$. In contrast, muscle transgene expression is often associated with cytolytic $\mathrm{CD}^{+} \mathrm{T}$ cell induction as well as humoral responses (37), and direct i.m. injection of rAAV vectors can be used to induce transgene immunization $(19,42)$. Of note, i.m. injection of a very high dose of $10^{11} \mathrm{vg}$ of rAAV8 was shown to lead to liver leakage and transgene unresponsiveness (43). However, no prior studies to our knowledge addressed the influence of concurrent muscle and liver transduction on the induction of transgene-specific tolerance for muscle applications, and no studies addressed under these circumstances whether preexisting immunity is deleterious for muscle transgene engraftment. We chose here to target simultaneously muscle and liver with a membrane form of OVA using a muscle-specific SPc5-12 promotor (44) and a hepatocyte-specific hAAT promotor, to evaluate the outcome of immunological crosstalk between muscle as an immunogenic delivery site and liver as a tolerogenic organ.

Monitoring the presence and phenotype of transgene-specific $\mathrm{CD} 8^{+} \mathrm{T}$ cells with tetramers, we found that dual muscle and hepatocyte OVA expression led to complete absence of OVA-specific CD8 ${ }^{+} \mathrm{T}$ cells in the liver, blood, and spleen. Surprisingly, we observed an accumulation of OVA-specific CD $8^{+} \mathrm{T}$ cells in the liver after a single muscle injection with our rAAV1/SPc5-12-mOVA muscle-specific vector, reflecting a transient accumulation of activated $\mathrm{CD}^{+} \mathrm{T}$ cells occurring in the liver independent of local antigen expression as previously noticed after immunization (36). These results indicate that activated OVA-specific $\mathrm{CD}^{+} \mathrm{T}$ cells generated by muscle transduction gain access to the liver tissue, where secondary cognate interactions with OVA antigen can take place, leading to either disposal or functional inactivation of OVA-specific $\mathrm{CD}^{+} \mathrm{T}$ cells. Indeed, $\mathrm{CD}^{+} \mathrm{T}$ cells have been shown to be disposed in the liver following antigen recognition through direct capture and internalization by hepatocytes in a mechanism referred to as suicidal emperipolesis (45). Moreover, apoptosis dependent on Bcl-2-like protein 11 (BIM) may also occur as a result of $\mathrm{T}$ cell-hepatocyte interactions (46). In addition, using OVA-specific TCR-transgenic $\mathrm{CD}^{+} \mathrm{T}$ cells (OT-1 cells), Tay et al. (34) showed that liver OVA expression can turn adoptively transferred OT-1 T cells into exhausted T cells expressing high levels of PD-1. Our results in the context of dual muscle-liver rAAV targeting demonstrate two potential outcomes for endogenous $\mathrm{CD}^{+} \mathrm{T}$ cells depending on the initial state of the host immune system with respect to the transgene. When mice were naive to the transgene, transgene-specific $\mathrm{CD} 8^{+} \mathrm{T}$ cells were absent from all tissues tested. When mice were primed to induce preexisting immunity to the transgene, we observed a massive reduction of OVA-specific $\mathrm{CD} 8^{+} \mathrm{T}$ cells in the spleen, with a remaining fraction of OVA-specific CD8 $8^{+} \mathrm{T}$ cells expressing high levels of PD-1 and somewhat higher levels of CD44, a feature found in exhausted CD8 ${ }^{+} \mathrm{T}$ cells but insufficient for a clear demonstration of their state. Assaying the function of these OVA-specific CD8 ${ }^{+} \mathrm{T}$ cells, we found that these $\mathrm{PD}-1^{\text {hi }} \mathrm{CD} 8^{+} \mathrm{T}$ cells did not produce IFN- $\gamma$ in response to antigen stimulation, a result that correlates with persistent transgene expression in muscle and advocates for their status as exhausted $\mathrm{CD} 8^{+} \mathrm{T}$ cells.

Studying the role of rAAV liver transduction doses, we initially found that a low dose of $10^{8} \mathrm{vg}$ of rAAV8/ mOVA-GFP vector in the liver induced an OVA-specific tetramer ${ }^{+} \mathrm{CD} 8^{+} \mathrm{T}$ cell response localized in the liver and was unable to impose tolerance to muscle-targeted transgene (data not shown). Likewise, studies performed by Kumar et al. (35) and Tay et al. (34) showed that low transgene expression in the liver and high avidity of the T cell for the transgene (34) leads to T cell activation after adoptive transfer of transgenic, OVA-specific 
$\mathrm{CD}^{+} \mathrm{T}$ cells. Along this line, Paul-Heng et al. have recently demonstrated in C57BL/6 mice that high liver expression of an intact allogenic MHCI H2- $\mathrm{K}^{\mathrm{d}}$ molecule allows indefinite survival of an allogenic $\mathrm{H} 2-\mathrm{K}^{\mathrm{d}}$ skin graft (27), whereas liver expression of a mutated $\mathrm{H} 2-\mathrm{K}^{\mathrm{d}}-\mathrm{D} 227 \mathrm{~K}$ transgene, which abrogates recognition of intact allogenic $\mathrm{MHCI}$ by $\mathrm{CD} 8^{+} \mathrm{T}$ cells, leads to partial skin graft survival. Consistent with our results, these studies indicate that liver transgene doses and interaction modalities of transgene-specific $\mathrm{CD} 8^{+} \mathrm{T}$ cells with transduced hepatocytes are critical for their fate. These features are specific to the combination of transgene and mouse strain under consideration and likely explain differences observed in the literature regarding the potency of liver tolerance examined with different transgenes and mouse strains $(31,47)$. Of importance, PaulHeng et al. showed that direct recognition of hepatocyte-expressed MHCI allogenic antigens is required for tolerance induction and skin engraftment (27). Our results demonstrate that processing of a defined muscle transgene by antigen-presenting cells of the host leads to $\mathrm{CD}^{+} \mathrm{T}$ cell responses, which are tolerized after recognition of hepatocyte-expressed host MHCI transgene complexes, even in presence of preexisting immunity.

As for monitoring the humoral response to the transgene, our study extends also to muscle-associated transgene results previously gathered with hFIX gene transfer (31). Humoral responses to the transgene were drastically reduced after dual muscle-liver transduction, but liminal levels of anti-OVA antibodies were nevertheless detected after tolerance induction in recipients preimmunized with OVA protein but not with $\mathrm{OVA}_{257}$ peptide (data not shown). Assessing the effect of OVA-specific CD4 ${ }^{+} \mathrm{T}$ cell responses on anti-OVA antibody production, we observed that preimmunization with the MHCII-restricted OVA epitope $\mathrm{OVA}_{323}$ peptide is effective to prime $\mathrm{CD} 4^{+} \mathrm{T}$ cells and enhances anti-OVA antibody production after $\mathrm{rAAV} / \mathrm{mOVA}$ muscle transfer, demonstrating the role of $\mathrm{CD}^{+} \mathrm{T}$ cell responses in humoral immunity to the transgene. Exploring the fate of transgene-specific $\mathrm{CD}^{+} \mathrm{T}$ cells generated after $\mathrm{OVA}_{323}$ peptide immunization, we found that dual muscle-liver transduction led to detectable anti-OVA ${ }_{323}$ IFN- $\gamma$-producing CD $4^{+}$ $\mathrm{T}$ cells but to barely detectable levels of the anti-OVA antibody response. Thus, of great interest for clinical situations where preexisting immunity to the transgene is encountered, the presence of anti-OVA CD4 ${ }^{+} \mathrm{T}$ cell responses did not impair the induction of $\mathrm{CD} 8^{+} \mathrm{T}$ cell and humoral tolerance. This result is compatible with a qualitative alteration of $\mathrm{CD}^{+} \mathrm{T}$ cells and with the fact that liver-based tolerance induction to FIX confers transferable tolerogenic properties to the $\mathrm{CD}^{+} \mathrm{T}$ cell compartment (31). Moreover, it was recently shown that liver expression of an autoantigen is able to induce autoantigen-specific regulatory $\mathrm{T}$ cells (Tregs), protecting mice from neuroinflammation in 2 models of multiple sclerosis $(48,49)$. In addition, it was found that rAAV hepatocytes' transduction of MHCI molecule $\mathrm{H} 2-\mathrm{K}^{\mathrm{d}}$ conditions C57BL/6 mice for successful transplantation of fully allogenic $\mathrm{H} 2-\mathrm{K}^{\mathrm{d}}$ pancreatic islets because of local liver expansion of a subset of $\mathrm{PD}-1^{+} \mathrm{CD} 8^{+} \mathrm{T}$ cell-harboring regulatory functions (50). Here, our model rAAV transgene system allowed us to recapitulate the effectiveness of liver-based tolerance induction in counteracting preexisting immune responses in multiple situations. Both preexisting humoral responses and $\mathrm{CD} 8^{+}$and $\mathrm{CD} 4^{+} \mathrm{T}$ cell responses were affected by dual muscle-liver transgene expression, with transgene-specific $\mathrm{CD}^{+} \mathrm{T}$ cells undergoing retention and/or depletion and exhaustion and transgene-specific $\mathrm{CD}^{+} \mathrm{T}$ cells remaining present but unable to boost antibody production. These $\mathrm{CD}^{+} \mathrm{T}$ cells are presumably forming a pool of cells able to undergo conversion into Foxp $3^{+}$Tregs, as evidenced in multiple sclerosis models $(48,49)$.

Overcoming muscle immune response to therapeutic transgenes is of importance in the treatment of muscular dystrophies. Muscle monogenic disorders can induce tissue inflammation and particularly in patients with DMD (25), where contraction-induced damages release cytoplasmic content that can stimulate innate immunity, promote chronic muscle inflammation, and worsen adverse immune responses to the therapeutic transgene (51). In this context, concurrent delivery of the transgene in muscle and liver is relevant to cope with adverse immune responses because of preexisting immunity. Future studies are required to develop dual muscle-liver antigen delivery protocols for dedicated muscular dystrophy applications.

\section{Methods}

Mice and in vivo injections. We purchased 6- to 8-week-old C57BL/6JRj male mice from JANVIER LABS, housed them under specific pathogen-free conditions in our animal facility (Centre d'exploration et de recherche fonctionnelle expérimentale, Evry, France), and them handled in accordance with French and European directives. For i.m. injection, mice were anesthetized using isoflurane, and indicated doses of rAAV vector, diluted in $25 \mu \mathrm{PBS}$, were injected into the left tibialis anterior using a 30-gauge RN Hamilton syringe. For i.v. injection, $200 \mu$ of the indicated rAAV vector diluted in PBS (to achieve desired vg doses) was injected into the caudal vein using a 0.5-ml insulin Myjector U-100 syringe (TERUMO). 
Plasmid constructions and rAAV vector productions. mOVA (19) cDNA were inserted by PCR in pSMD2 rAAV1 or rAAV8 plasmid between the SPc5-12 muscle-specific promoter or hAAT hepatocyte-specific promotor and a polyA signal to create $\mathrm{rAAV1/SPc5-12-mOVA} \mathrm{(rAAV1/mOVA)} \mathrm{targeting} \mathrm{the} \mathrm{muscle} \mathrm{or}$ rAAV8/hAAT-mOVA (rAAV8/mOVA) targeting the liver, respectively. Alternatively, the full-length cDNA sequence for the GFP was fused to the transmembrane domain of the $m O V A$ cDNA, to create a mOVAGFP sequence and, as described above, rAAV1/SPc5-12-mOVA-GFP (rAAV1/mOVA-GFP) and rAAV8/ hAAT-mOVA-GFP (rAAV8/mOVA-GFP). All AAV vectors used in this study were produced using an adenovirus-free, transient transfection method and purified as described previously (52). Titers of the AAV vector stocks were determined using real-time quantitative PCR and confirmed by SDS-PAGE, followed by SYPRO Ruby Protein Gel Stain and band densitometry.

Quantification of OVA $m R N A$. Total RNA were extracted from 20 frozen 12- $\mu \mathrm{m}$ sections of each organ using the Nucleospin RNA plus kit (MACHEREY-NAGEL). For quantification of OVA mRNA, 100 ng of total RNA was reverse-transcribed using Superscript II kit (Invitrogen). Then $4 \mu 1$ of reverse transcription PCR product was subjected to real-time PCR amplification using OVA forward (5'-AAGCAGGCAGAGAGGTGGTA-3'), OVA reverse (5'-GAATGGATGGTCAGCCCTAA-3'), $\beta$-actin forward (5'-AAGATCTGGCACCACACCTTCT-3'), and $\beta$-actin reverse (5'-TTTTCACGGTTGGCCTTAGG-3') primers. All reaction mixtures were made according to QuantiFast SYBR Green PCR Kit instructions (QIAGEN); OVA primers were used at $500 \mathrm{nmol} / \mathrm{L}$ and $\beta$-actin primers at $400 \mathrm{nmol} / \mathrm{L}$ as described previously (53). The absolute amount of $O V A$ mRNA for each sample was calculated and normalized using the $\Delta \Delta \mathrm{Ct}$ formu-

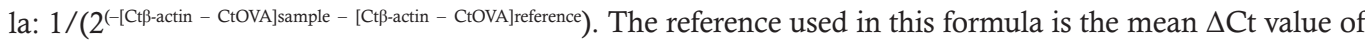
the double-injected rAAV1/mOVA i.m. and $\mathrm{rAAV} 8 / \mathrm{mOVA}$ i.v. group defined in each experiment.

Lymphocyte isolation. For peripheral blood lymphocyte isolation, erythrocytes were eliminated by hypotonic shock with BD Pharm Lyse buffer (BD Biosciences). For splenocyte isolation, spleen was crushed manually in $1 \times$ PBS with $0.1 \%$ HSA. For isolation of lymphocytes from liver, liver was collected and crushed manually in $1 \times$ PBS $0.1 \%$ HSA, then resuspended in $4 \mathrm{ml}$ of $1 \times$ PBS $0.1 \%$ HSA and spun at $30 \mathrm{~g}$ for 2 minutes at $4^{\circ} \mathrm{C}$ to eliminate cellular debris. Supernatant was spun at $300 \mathrm{~g}$ for 5 minutes at $4^{\circ} \mathrm{C}$. The cell pellet was resuspended in 40\% Percoll (MilliporeSigma) at room temperature. We then added $2 \mathrm{ml}$ of $70 \%$ Percoll solution at room temperature below the $40 \%$ cell suspension. Percoll gradient was centrifuged at $1300 \mathrm{~g}$ for 20 minutes at room temperature with no break. The upper fat layer was removed, and the interface cell band was collected.

Flow cytometry analysis. For tetramer staining, we followed our method previously described (54, 55). Briefly, cell suspensions were first incubated with iTAg Tetramer/PE - H-2 Kb OVA (TB-5001-1, Clinisciences) for 30 minutes at room temperature, then blocked with anti-CD16/CD32 antibody (2.4G2, Bio $\mathrm{X}$ Cell) for 10 minutes at $4^{\circ} \mathrm{C}$ followed by membrane staining for 15 minutes at $4^{\circ} \mathrm{C}$ using a combination of BV421 or APC anti-CD8 $\alpha$ (53-6.7), FITC anti-CD44 (IM7), BV421 anti-PD-1 (29F.1A12), and PE/Cy7 anti-CD4 (RM4-5) (all antibodies from BioLegend).

For intracellular staining, cell suspensions were first blocked with anti-CD16/CD32 antibody (2.4G2, Bio X Cell) for 10 minutes at $4^{\circ} \mathrm{C}$, followed by membrane staining for 15 minutes at $4^{\circ} \mathrm{C}$ using a combination of FITC anti-CD44 (IM7), V500 anti-CD4 (RM4-5), PE/Cy7 anti-CD8 $\alpha$ (53-6.7), and BV421 anti-PD-1 (29F.1A12). Second, cells were fixed and permeabilized using eBioscience Fixation/Permeabilization Concentrate (Thermo Fisher Scientific) according to the manufacturer's instructions. Permeabilized cells were then blocked with anti-CD16/CD32 antibody (2.4G2, Bio X Cell) for 15 minutes at $4^{\circ} \mathrm{C}$, followed by intracellular staining performed in permeabilization buffer (eBioscience) for 30 minutes at $4^{\circ} \mathrm{C}$ using PE anti-Foxp3 (FJK-16a) and APC anti-IFN- $\gamma$ (XMG1.2) (both from BioLegend).

In both cases, dead cells were excluded using the LIVE/DEAD Fixable Near-IR Dead Cell Stain Kit (Life Technologies). Data were collected on an LSRII Fortessa flow cytometer and further analyzed using FlowJo software (Tree Star Inc). All antibodies were purchased from BioLegend unless stated otherwise.

Anti-OVA IgG ELISA. ELISA plates (BD Falcon Microtest 96-well ELISA plate, clear) were coated overnight with $50 \mu \mathrm{l} /$ well of a $10 \mu \mathrm{g} / \mathrm{ml}$ dilution of OVA protein (MilliporeSigma) in carbonate buffer, pH 9.5 (freshly prepared from carbonate and bicarbonate powder from MilliporeSigma). Plates were then washed 3 times with $1 \times$ PBS $0.05 \%$ Tween and blocked for 2 hours with blocking buffer, $1 \times$ PBS $2 \%$ BSA, at room temperature and washed 3 times. Serial dilutions of experimental sera, as well as of a reference serum from mice immunized with OVA protein emulsified in IFA (BD Difco), were prepared in blocking 
buffer as above and incubated in 96-well plates for 1 hour at $37^{\circ} \mathrm{C}$. Then, the plates were washed 2 times, and bound anti-OVA IgG was incubated with $100 \mu 1$ of biotinylated horse anti-mouse IgG (Vector Laboratories, Eurobio) diluted 1:4000 in blocking buffer. Plates were then washed 2 times and incubated with $100 \mu 1$ /well of HRP avidin (Vector Laboratories, Eurobio), diluted 1:4000 in blocking buffer for 30 minutes at room temperature, and washed again 3 times. Finally, anti-OVA IgG was revealed with TMB substrate reagent set (BD Biosciences). The reaction was stopped after 3-5 minutes with $50 \mu \mathrm{l} /$ well of $2 \mathrm{~N} \mathrm{H}_{2} \mathrm{SO}_{4}$, and the absorbance at $450 \mathrm{~nm}$ was determined. Antibodies' levels are represented as a ratio of sample dilution over the reference serum dilution corresponding to the same optical densities, considering a linear range in standard curve.

Statistics. All data are shown as mean \pm SEM. For statistical analyses, Mann-Whitney tests were performed for comparing independent groups 2 by 2, and Kruskal-Wallis tests followed by Dunn's multiple-comparisons tests were performed to compare multiple groups. Data were considered significant when $P$ values were less than 0.05 and considered nonsignificant when $P$ values were greater than 0.05 .

Study approval. Mouse studies were performed in accordance with the current European legislation on animal care and experimentation $(2010 / 63 / \mathrm{EU})$ and approved by the institutional ethics committee of the Centre d'Exploration et de Recherche Fonctionnelle Expérimentale (protocol APAFIS 305520151019213299180).

\section{Author contributions}

LB performed all the rAAV vector constructions, handled mouse experimentation, and performed all experiments, the majority of endpoint analyses, and statistical analyses. GR, IR, and FM provided assistance with rAAV vector constructions, animal experimentation, and experimental design. LB and J. Davoust wrote the manuscript with the help of J. Demengeot, FM, DAG, and P. Chappert. SLCT assisted in many of the experiments, including ELISA and quantitative PCR analyses, whereas P. Colella, FC, and FM prepared the rAAV vector batches, and DU assisted SLCT with frozen section aspects of the quantitative PCR analyses. J. Davoust, J. Demengeot, and FM contributed funding. P. Chappert and DAG advised on flow analysis and on mouse experimentation. J. Davoust oversaw all aspects of experimental design, data analysis, literature research, and manuscript writing and contributed funding to this project.

\section{Acknowledgments}

We thank Corinne Tanchot, Oumeya Adjali, Sahil Adriouch, Julien Zuber, and Sebastien Storck for helpful discussions; Anne-Perrine Foray and Coralie Pecquet for experimental help; and Hildegard Büning for critically reading the manuscript. This work was supported by the CNRS, the INSERM, the Universite Paris Descartes, the Association Française contre les Myopathies grant 19617, and the European Union, ERC-2013-CoG Consolidator Grant, grant agreement number 617432 (MoMAAV); and research and innovation program under grant agreement number 667751 (Myocure). LB was supported by the French Ministry of Research.

Address correspondence to: Jean Davoust, INSERM U1151 - CNRS UMR 8253, Hôpital Necker-Enfants Malades, Bâtiment Hamburger, 149 rue de Sèvres, 75015 Paris, France. Phone: 33.0.1.44.38.15.05; Email: jean.davoust@inserm.fr.

1. Aguti S, Malerba A, Zhou H. The progress of AAV-mediated gene therapy in neuromuscular disorders. Expert Opin Biol Ther. 2018;18(6):681-693

2. Day TP, Byrne LC, Schaffer DV, Flannery JG. Advances in AAV vector development for gene therapy in the retina. Adv Exp Med Biol. 2014;801:687-693.

3. Hocquemiller M, Giersch L, Audrain M, Parker S, Cartier N. Adeno-associated virus-based gene therapy for CNS diseases. Hum Gene Ther. 2016;27(7):478-496.

4. Chuah MK, Evens H, VandenDriessche T. Gene therapy for hemophilia. J Thromb Haemost. 2013;11(suppl 1):99-110.

5. Mingozzi F, et al. CD8(+) T-cell responses to adeno-associated virus capsid in humans. Nat Med. 2007;13(4):419-422

6. Veron $P$, et al. Humoral and cellular capsid-specific immune responses to adeno-associated virus type 1 in randomized healthy donors. J Immunol. 2012;188(12):6418-6424.

7. Scallan CD, et al. Human immunoglobulin inhibits liver transduction by AAV vectors at low AAV2 neutralizing titers in SCID mice. Blood. 2006;107(5):1810-1817.

8. Büning H, Srivastava A. Capsid modifications for targeting and improving the efficacy of AAV vectors. Mol Ther Methods Clin Dev. 2019;12:248-265 
9. Meliani A, et al. Antigen-selective modulation of AAV immunogenicity with tolerogenic rapamycin nanoparticles enables successful vector re-administration. Nat Commun. 2018;9(1):4098.

10. Manno CS, et al. Successful transduction of liver in hemophilia by AAV-Factor IX and limitations imposed by the host immune response. Nat Med. 2006;12(3):342-347.

11. Mingozzi F, High KA. Overcoming the host immune response to adeno-associated virus gene delivery vectors: the race between clearance, tolerance, neutralization, and escape. Annu Rev Virol. 2017;4(1):511-534.

12. Mays LE, Wilson JM. The complex and evolving story of T cell activation to AAV vector-encoded transgene products. Mol Ther. 2011;19(1):16-27.

13. Annoni A, et al. Liver gene therapy by lentiviral vectors reverses anti-factor IX pre-existing immunity in haemophilic mice. EMBO Mol Med. 2013;5(11):1684-1697.

14. Markusic DM, et al. Effective gene therapy for haemophilic mice with pathogenic factor IX antibodies. EMBO Mol Med. 2013;5(11):1698-1709.

15. Fields PA, et al. Risk and prevention of anti-factor IX formation in AAV-mediated gene transfer in the context of a large deletion of F9. Mol Ther. 2001;4(3):201-210.

16. Wang L, Cao O, Swalm B, Dobrzynski E, Mingozzi F, Herzog RW. Major role of local immune responses in antibody formation to factor IX in AAV gene transfer. Gene Ther. 2005;12(19):1453-1464.

17. Nayak S, et al. Prevention and reversal of antibody responses against factor IX in gene therapy for hemophilia B. Front Microbiol. $2011 ; 2: 244$

18. Herzog RW. Complexity of immune responses to AAV transgene products - example of factor IX [published online ahead of print May 29, 2017]. Cell Immunol. doi: 10.1016/j.cellimm.2017.05.006.

19. Carpentier M, et al. Intrinsic transgene immunogenicity gears CD8(+) T-cell priming after rAAV-mediated muscle gene transfer. Mol Ther. 2015;23(4):697-706.

20. Yuasa K, et al. Injection of a recombinant AAV serotype 2 into canine skeletal muscles evokes strong immune responses against transgene products. Gene Ther. 2007;14(17):1249-1260.

21. Dressman D, et al. Delivery of $\alpha$ - and $\beta$-sarcoglycan by recombinant adeno-associated virus: efficient rescue of muscle, but differential toxicity. Hum Gene Ther. 2002;13(13):1631-1646.

22. Yuasa K, et al. Adeno-associated virus vector-mediated gene transfer into dystrophin-deficient skeletal muscles evokes enhanced immune response against the transgene product. Gene Ther. 2002;9(23):1576-1588.

23. Ginhoux F, et al. Identification of an HLA-A*0201-restricted epitopic peptide from human dystrophin: application in duchenne muscular dystrophy gene therapy. Mol Ther. 2003;8(2):274-283.

24. Flanigan KM, et al. Anti-dystrophin T cell responses in Duchenne muscular dystrophy: prevalence and a glucocorticoid treatment effect. Hum Gene Ther. 2013;24(9):797-806.

25. Mendell JR, et al. Dystrophin immunity in Duchenne's muscular dystrophy. N Engl J Med. 2010;363(15):1429-1437.

26. Cunningham EC, et al. Gene therapy for tolerance: high-level expression of donor major histocompatibility complex in the liver overcomes naive and memory alloresponses to skin grafts. Transplantation. 2013;95(1):70-77.

27. Paul-Heng M, et al. Direct recognition of hepatocyte-expressed MHC class I alloantigens is required for tolerance induction. JCI Insight. 2018;3(15):97500.

28. Mak KY, Rajapaksha IG, Angus PW, Herath CB. The adeno-associated virus - a safe and promising vehicle for liverspecific gene therapy of inherited and non-inherited disorders. Curr Gene Ther. 2017;17(1):4-16.

29. LoDuca PA, Hoffman BE, Herzog RW. Hepatic gene transfer as a means of tolerance induction to transgene products. Curr Gene Ther. 2009;9(2):104-114.

30. Franco LM, et al. Evasion of immune responses to introduced human acid alpha-glucosidase by liver-restricted expression in glycogen storage disease type II. Mol Ther. 2005;12(5):876-884.

31. Mingozzi F, et al. Induction of immune tolerance to coagulation factor IX antigen by in vivo hepatic gene transfer. J Clin Invest. 2003;111(9):1347-1356.

32. Bowen DG, Zen M, Holz L, Davis T, McCaughan GW, Bertolino P. The site of primary T cell activation is a determinant of the balance between intrahepatic tolerance and immunity. J Clin Invest. 2004;114(5):701-712.

33. Ziegler RJ, et al. AAV2 vector harboring a liver-restricted promoter facilitates sustained expression of therapeutic levels of alpha-galactosidase A and the induction of immune tolerance in Fabry mice. Mol Ther. 2004;9(2):231-240.

34. Tay SS, et al. Antigen expression level threshold tunes the fate of CD8 T cells during primary hepatic immune responses. Proc Natl Acad Sci U S A. 2014;111(25):E2540-E2549.

35. Kumar SRP, Hoffman BE, Terhorst C, de Jong YP, Herzog RW. The balance between CD8. Mol Ther. 2017;25(4):880-891

36. John B, Crispe IN. Passive and active mechanisms trap activated CD ${ }^{+}$T cells in the liver. J Immunol. 2004;172(9):5222-5229.

37. Wang Z, Tapscott SJ, Chamberlain JS, Storb R. Immunity and AAV-mediated gene therapy for muscular dystrophies in large animal models and human trials. Front Microbiol. 2011;2:201.

38. Hoffman BE, et al. Muscle as a target for supplementary factor IX gene transfer. Hum Gene Ther. 2007;18(7):603-613.

39. Thomson AW, Knolle PA. Antigen-presenting cell function in the tolerogenic liver environment. Nat Rev Immunol. 2010;10(11):753-766.

40. Jenne CN, Kubes P. Immune surveillance by the liver. Nat Immunol. 2013;14(10):996-1006.

41. Horst AK, Neumann K, Diehl L, Tiegs G. Modulation of liver tolerance by conventional and nonconventional antigen-presenting cells and regulatory immune cells. Cell Mol Immunol. 2016;13(3):277-292.

42. Manning WC, et al. Genetic immunization with adeno-associated virus vectors expressing herpes simplex virus type 2 glycoproteins B and D. J Virol. 1997;71(10):7960-7962.

43. Mays LE, et al. AAV8 induces tolerance in murine muscle as a result of poor APC transduction, $\mathrm{T}$ cell exhaustion, and minimal MHCI upregulation on target cells. Mol Ther. 2014;22(1):28-41.

44. Li X, Eastman EM, Schwartz RJ, Draghia-Akli R. Synthetic muscle promoters: activities exceeding naturally occurring regulatory sequences. Nat Biotechnol. 1999;17(3):241-245.

45. Benseler V, et al. Hepatocyte entry leads to degradation of autoreactive CD8 T cells. Proc Natl Acad Sci U S A. 
2011;108(40):16735-16740.

46. Holz LE, et al. Intrahepatic murine CD8 T-cell activation associates with a distinct phenotype leading to Bim-dependent death. Gastroenterology. 2008;135(3):989-997.

47. Breous E, Somanathan S, Wilson JM. BALB/c mice show impaired hepatic tolerogenic response following AAV gene transfer to the liver. Mol Ther. 2010;18(4):766-774.

48. Lüth S, et al. Ectopic expression of neural autoantigen in mouse liver suppresses experimental autoimmune neuroinflammation by inducing antigen-specific Tregs. J Clin Invest. 2008;118(10):3403-3410.

49. Keeler GD, et al. Gene therapy-induced antigen-specific Tregs inhibit neuro-inflammation and reverse disease in a mouse model of multiple sclerosis. Mol Ther. 2018;26(1):173-183.

50. Le Guen V, et al. Alloantigen gene transfer to hepatocytes promotes tolerance to pancreatic islet graft by inducing CD8. J Hepatol. 2017;66(4):765-777.

51. Rosenberg AS, et al. Immune-mediated pathology in Duchenne muscular dystrophy. Sci Transl Med. 2015;7(299):299rv4

52. Vidal P, et al. Rescue of GSDIII phenotype with gene transfer requires liver- and muscle-targeted GDE expression. Mol Ther. 2018;26(3):890-901

53. Adriouch $\mathrm{S}$, et al. Improved immunological tolerance following combination therapy with CTLA-4/Ig and AAV-mediated PD-L1/2 muscle gene transfer. Front Microbiol. 2011;2:199.

54. Ghenassia A, et al. Intradermal immunization with rAAV1 vector induces robust memory CD8. Mol Ther. 2017;25(10):2309-2322

55. Gross DA, et al. Cross-presentation of skin-targeted recombinant adeno-associated virus $2 / 1$ transgene induces potent resident memory CD8+ T cell responses. J Virol. 2019;93(5):e01334-18. 